\title{
EFFECT OF HANDEDNESS ON FUNCTIONAL ORGANIZATION OF BIMANUAL ISOMETRIC HANDGRIP
}

\author{
Nikolai V. Kolev, \\ Ljudmila I. Halacheva
}

\author{
Department of Physiology and \\ Pathophysiology, \\ Medical University - Pleven
}

\author{
Corresponding Author: \\ Nikolai Kolev \\ Department of Physiology and \\ Pathophysiology \\ Faculty of Medicine \\ Medical University - Pleven \\ e-mail: dr_n_kolev@abv.bg
}

Received: November 27, 2014

Revision received: February 04, 2015

Accepted: May 18, 2015

\begin{abstract}
Summary
The aim of this study was to examine force production during maximal isometric handgrip in unilateral (UL) and bilateral (BL) tasks in right- and left-handed subjects. Ten right-handed $(\mathrm{RH})$ and 8 left-handed $(\mathrm{LH})$ young men were studied. The subjects were instructed, after a command, to perform a shot-like handgrip, raising maximal force as fast as possible. Three series were performed as follows: 1) UL - right handgrip; 2) UL - left handgrip; 3) BL handgrip. We measured peak force, time to peak of force and rate of force. The BL/UL ratios for the right (R) and left (L) hand and $\mathrm{L} / \mathrm{R}$ ratios for the $\mathrm{UL}$ and BL tasks were calculated. The $\mathrm{L} / \mathrm{R}$ ratios for peak force and force rate in RH group ranged across all tasks and conditions from 0.71 to 0.75 . They were significantly lower than $1 \quad(p<0.01)$. These ratios did not differ significantly from 1 for LH subjects (0.98-1.02), indicating the handedness in RH group only. The BL/UL ratios for peak force were 0.89 and 0.89 in $\mathrm{RH}$, suggesting symmetrical bilateral strength deficit. The magnitude of the bilateral deficit in LH group was larger for the dominant $(\mathrm{L})$ hand compared to non dominant $(\mathrm{R})$ hand 0.93 and $0.97 \quad(p<0.05)$ respectively, suggesting an asymmetry of bilateral deficit in LH. These ratios for time of force and rate of force indicated bilateral deficit (BD) in the dominant hand of RH group only.
\end{abstract}

Key words: handgrip, maximal force, bilateral deficit, handedness

\section{Introduction}

The upper limbs and the hands in particular, prove paramount to daily life. The hand has a central role in many activities like writing, typing, eating, sports activities, etc. People use one of their hands dominantly. Handedness is perhaps the most flagrant behavioral asymmetry observed in humans [1]. Hand dominance implies that one hand is preferred and used for performing specific motor tasks. Preference to use the right hand is seen in approximately $90 \%$ of the population and left-handedness is seen in the remainder 10\% [2]. Measurement of maximal grip strength is an important component in hand evaluation. Grip strength is also a reliable marker in assessing possible functional differences between 
the dominant and the non-dominant hand. The ratio obtained by dividing the maximal strength of the left hand by the maximal strength of the right hand demonstrates the differences between the hands. The 10 percent rule states that the strength of the dominant hand is $10 \%$ greater than that of the non-dominant hand [3]. Clerke and Clerke (2001) reviewed the literature on handedness and maximal grip strength. They found a wide variation in reported strength ratios between dominant and non-dominant hand, ranging from zero to 40 percent [4]. Some authors have concluded that right-handed subjects are significantly stronger on the dominant side whereas such greater strength on the dominant side is not found in left-handed individuals [5, 6]. In contrast, Ertem et al. (2003) reported that the 10 percent rule was found to be valid for left-handed persons only [7]. However, Koley and Singh (2010) confirmed the 10 percent rule for both hands in groups of right- and lefthanded males and females [8]. These data suggest that it is important to consider handedness when assessing grip strength.

A manual task may be performed either by unilateral functioning of an arm, or by bilateral functioning of both arms. To hold, pull or push heavy objects, we often maximally contract finger flexors, elbow flexors or extensors of both arms simultaneously to apply the greatest force. Many investigators have reported a reduction in maximal voluntary strength induced on simultaneous bilateral exertion as compared with the sum of left and right unilateral limb actions. This phenomenon is known as bilateral deficit (BD) [9]. BD has been observed in both upper [9, 10] and lower limbs [11, 12]. The mechanism responsible for the bilateral deficit is currently unknown. Some studies have shown a left/right asymmetry of bilateral deficit $[9,10]$. These studies claim that the bilateral strength deficit is greater for the dominant right hand than for the non-dominant left hand, but this was not confirmed thereafter [13]. This controversy might be due to differences related to age, training and handedness. Unfortunately, little experimental information is available on influence of handedness on the BD.

The aim of the present study was to test the bimanual organization of maximal shot-like isometric handgrip in right- and left-handed young men. Apart from peak force, we measured time to peak force and the rate of force development.

\section{Methods}

We examined isometric force production during shot-like handgrip in performance of unilateral and bilateral tasks. Ten healthy right-handed (age range 19-24 years) and eight healthy left-handed (age range 19-24 years) young men were studied (Table 1). They signed informed consent forms to participate in the experiment. Subjects were not paid for their participation. Handedness was determined by questioning them [14]. An experimental subject was seated in an armchair with arms along the body, forearms flexed (90degree elbow flexion) and semipronated, with wrists supported. Each subject was instructed to make a shot-like handgrip after a command, developing maximal force as fast as possible and to act only with forearm and hand flexors, not involving elbow flexors and shoulder muscles. The grip force exerted between 4 fingers and the thumb was measured with a force transducer connected to a dual-beam oscilloscope. Three series in random order were performed as follows: 1) unilateral (UL) right handgrip; 2) UL left handgrip; 3) bilateral (BL) handgrip.

We measured peak force and time to peak of force. The rate of force was calculated as a quotient of the peak force to the time of force

Table 1. Group mean values \pm SD for age, height, weight and Body Mass Index

\begin{tabular}{cccccc}
\hline GROUP & N & Age (years) & Heieight (cm) & Weight (kg) & BMI \\
\hline R-handed & 10 & $20.3 \pm 1.5$ & $181.7 \pm 6.3$ & $78.3 \pm 10.6$ & $23.67 \pm 2.5$ \\
\hline L-handed & 8 & $20.8 \pm 3.4$ & $181.2 \pm 6.7$ & $72,8 \pm 6.1$ & $22.36 \pm 2.9$ \\
\hline
\end{tabular}


(Figure 1). The BL/UL ratios for the right (R) and left $(\mathrm{L})$ hand and the $\mathrm{L} / \mathrm{R}$ ratios for the UL and BL tasks were calculated.

A 1-sample t-test against 1 was used to determine if the average ratio for each task was significantly different from 1 . The main effects of the handedness (right-handed and left-handed) as well of hand (R and L) or task (UL and BL) were evaluated by ANOVA. In each case significance was accepted at $\mathrm{p}<0.05$.

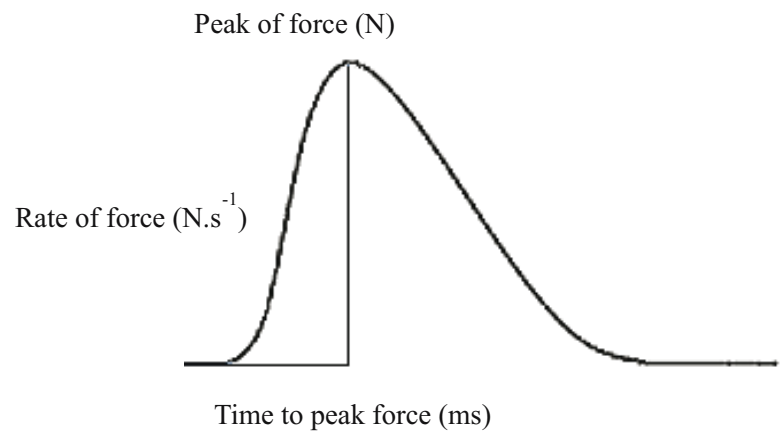

Figure 1. Shot-like isometric handgrip

\section{Results}

Table 2 shows group mean values \pm SEM for peak force, time to peak force and rate of force. The ANOVA revealed significantly higher rate of force for left hand in left-handed group, as compared with left hand of right-handers in both $\mathrm{UL}$ and BL tasks $(\mathrm{p}<0.05)$. The right-handed subjects showed a slightly stronger peak force and force rate for their dominant $\mathrm{R}$ hand than the non-dominant $\mathrm{R}$ hand in the left-dominant individuals (NS). There were no significant differences between the two groups in relation to time to peak force.

The $\mathrm{L} / \mathrm{R}$ ratios (Figure 2) for peak of force and rate of force ranged across all tasks and conditions from 0.71 to 0.75 in the group of righthanded men. These ratios were significantly lower than $1 \quad(\mathrm{p}<0.01)$ and they did not significantly differ from 1 in the left-handed group (0.98-1.02).

The $\mathrm{L} / \mathrm{R}$ ratios for time to peak of force ranged across 1.0 to 1.04 in both groups. They did not differ significantly from 1 suggesting a functional bilateral symmetry for this measure.

The BL/UL ratios (Figure 3) for peak of force were in right handed group -0.89 and 0.89 , while in the left dominant group they were -0.97 and 0.94 for $\mathrm{R}$ and $\mathrm{L}$ hand, respectively. These ratios were significantly lower than $1(\mathrm{p}<0.05)$ and showed symmetrical bilateral deficit (BD) in right handed subjects. The BL/UL ratios for peak of force in left handed men were significantly lower than 1 for their dominant $\mathrm{L}$ hand $(\mathrm{p}<0.05)$ and they did not differ significantly from 1 for the non-dominant right hand suggesting an asymmetry of the BLD in left-handed participants.

The BL/UL ratios for time to peak force were in the right-handed group -0.92 and 0.95 , while in the left-handed group they were 1.00 and 0.97 for $\mathrm{R}$ and $\mathrm{L}$ hand, respectively. They were significantly different from $1(\mathrm{p}<0.05)$ in $\mathrm{RH}$ group, indicating $\mathrm{BD}$ for this parameter in the right-handers only. The BL/UL ratios for rate of force did not differ significantly from 1 in the lefthanded group -0.97 and 0.96 for $\mathrm{R}$ and $\mathrm{L}$ hand, respectively. These ratios in the $\mathrm{RH}$ group were significantly closer to 1 for the left hand -0.97 (NS), as compared to right hand $-0.94(p<0.05)$ indicating $\mathrm{BD}$ of the power of handgrip in the dominant right hand.

Table 2. Group mean values \pm SEM for Peak force, Time to peak force and Rate of force

\begin{tabular}{|c|c|c|c|c|c|c|c|c|c|c|c|c|}
\hline \multirow{2}{*}{ GROUP } & \multicolumn{4}{|c|}{ Peak force (N) } & \multicolumn{4}{|c|}{ Time to peak force (ms) } & \multicolumn{4}{|c|}{ Force rate $\left(\mathrm{N} . \mathrm{s}^{-1}\right)$} \\
\hline & LUL & LBL & RUL & RBL & LUL & LBL & RUL & RBL & LUL & LBL & RUL & RBL \\
\hline R-handed & $\begin{array}{r}267.6 \\
\pm 18.2\end{array}$ & $\begin{array}{l}240.7 \\
\pm 20.0\end{array}$ & $\begin{array}{r}370.6 \\
\pm 32.3\end{array}$ & $\begin{array}{l}331.5 \\
\pm 32.6\end{array}$ & $\begin{array}{l}196.9 \\
\pm 6.4\end{array}$ & $\begin{array}{l}181.8 \\
\pm 8.9\end{array}$ & $\begin{array}{l}190.2 \\
\pm 9.1\end{array}$ & $\begin{array}{l}180.2 \\
\pm 8.3\end{array}$ & $\begin{array}{l}1350 \\
\pm 61\end{array}$ & $\begin{array}{l}1309 \\
\pm 63\end{array}$ & $\begin{array}{l}1922 \\
\pm 93\end{array}$ & $\begin{array}{r}1810 \\
\pm 106\end{array}$ \\
\hline $\begin{array}{c}\text { L- } \\
\text { handed }\end{array}$ & $\begin{array}{l}310.1 \\
\pm 20.3\end{array}$ & $\begin{array}{c}289.4 \\
\pm 23.6\end{array}$ & $\begin{array}{r}303.8 \\
\pm 19.9\end{array}$ & $\begin{array}{l}295.8 \\
\pm 20.1\end{array}$ & $\begin{array}{c}190.6 \\
\pm \\
11.5\end{array}$ & $\begin{array}{r}185,2 \\
\pm 13,9\end{array}$ & $\begin{array}{r}184.2 \\
\pm 12.1\end{array}$ & $\begin{array}{l}184.1 \\
\pm 11.4\end{array}$ & $\begin{array}{l}1631 \\
\pm 75\end{array}$ & $\begin{array}{l}1569 \\
\pm 86\end{array}$ & $\begin{array}{r}1663 \\
\pm 117\end{array}$ & $\begin{array}{r}1620 \\
\pm 119\end{array}$ \\
\hline
\end{tabular}




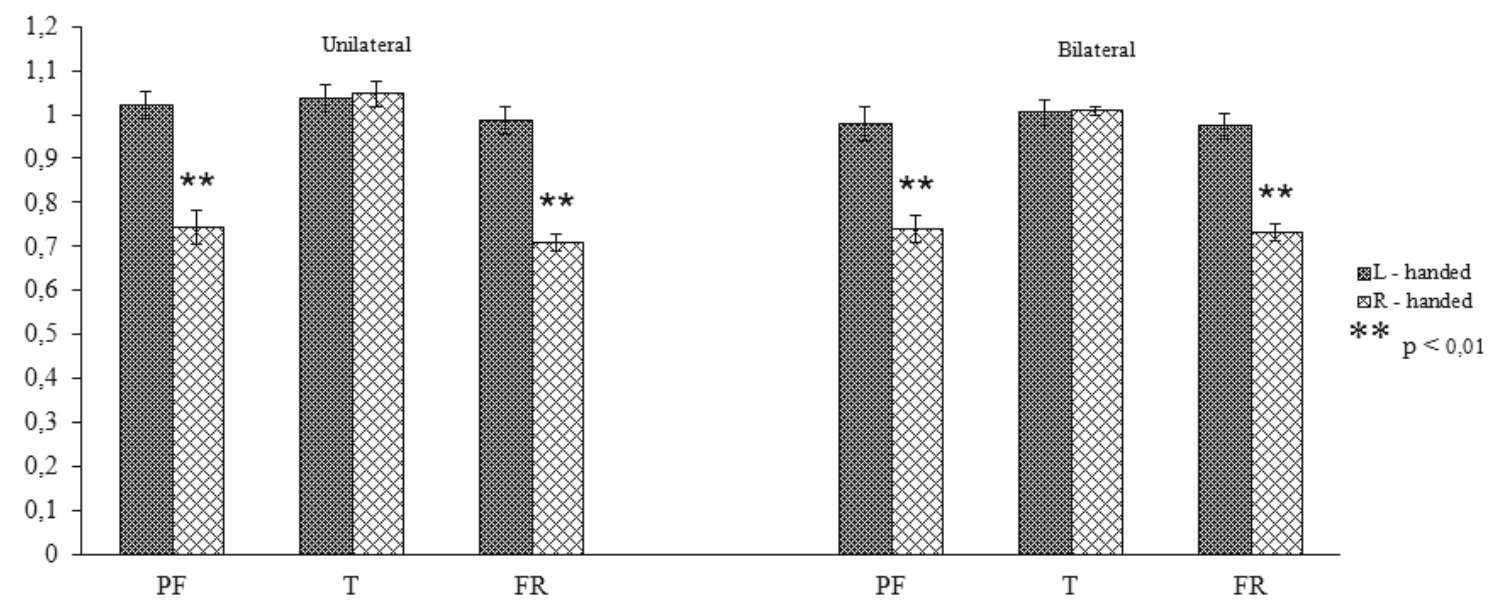

Figure 2. Handedness - L/R ratios for Peak of force (PF), Time to Peak of force (T), Rate of force (FR)

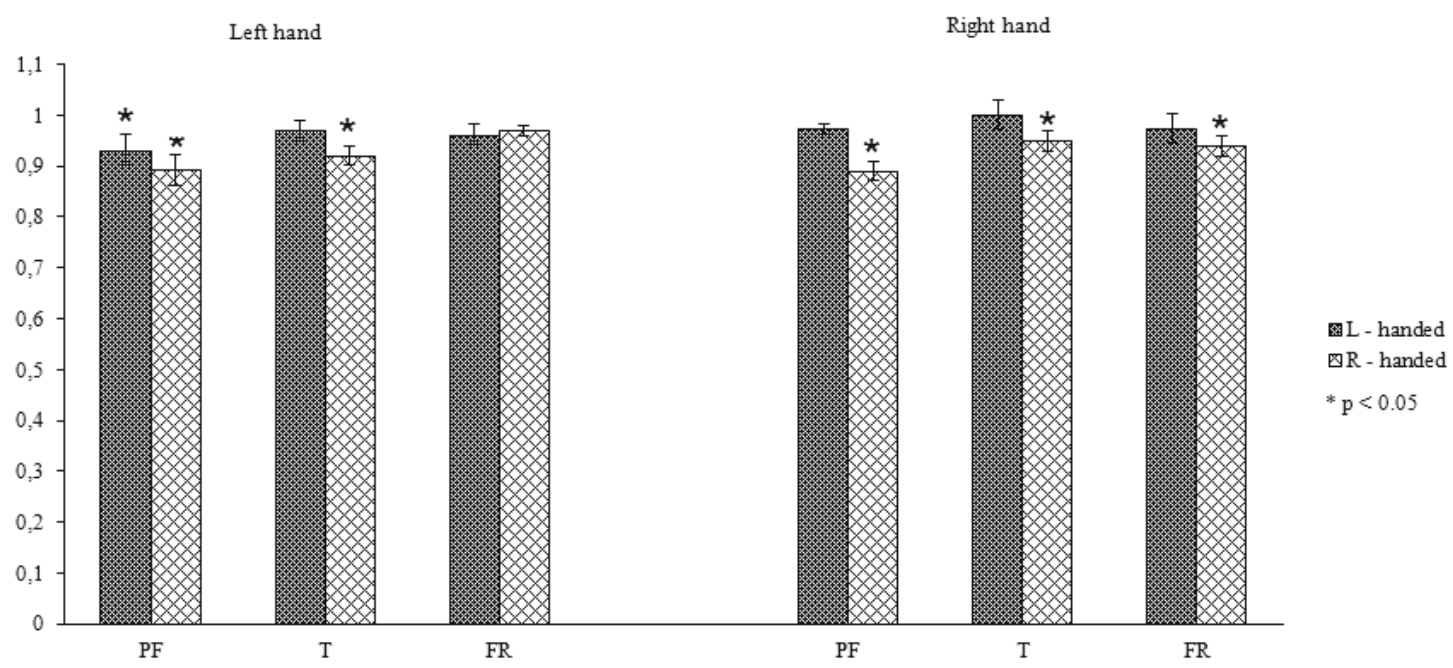

Figure 3. Bilateral deficit - BL/UL ratios for Peak of force (PF), Time to Peak of force (T), Rate force (FR)

\section{Discussion}

The more powerful handgrip contraction found for the dominant left hand in the left-handed individuals as compared with non-dominant left hand of their right-handed mates was in line with the finding that the grip strength of right-handed subjects increased with age peaking in subjects aged 18 to 34 years whereas in the left-handed group, maximum strength occurred in age group 18 to 24 years [15].

The $L / R$ ratios for peak of force and rate of force in the left handed group were significantly closer to 1 , as compared to the right-handers. The general rule which is often used suggests that the dominant hand is approximately $10 \%$ stronger than the non-dominant hand. The results for right the right hand was significantly stronger and more powerful than the left hand. However, for left handed individuals this was not true. Our results supported the findings of Bohannon (2003) and Oppewal (2013) who reported that right-handed subjects were stronger with their right hand, whereas for left-handed participants there was no significant difference in strength between the dominant and non-dominant hand [5, 6]. On the other hand, Ertem et al.(2003) pointed out that the 10 percent rule was valid for lefthanded persons only [7]. Our results were totally different from the findings reported by Ertem et al. (2003). In the present study the peak of force and the rate of force were found indicative parameters for handedness in the right-handed group only. This difference may be explained by the fact that the world we live in is mostly 
designed for right handedness. Most tools and appliances are designed for the right handed people. As a result, the right hand of both rightand left-handed people is exercised more often than the left hand on a daily basis [8].

The symmetrical bilateral deficit for peak of force and time to peak of force found in right handed subjects confirmed the findings of Van Dieën et al. (2003), who reported significant bilateral deficits in voluntary finger flexion force of about $20 \%$ for both $\mathrm{L}$ and $\mathrm{R}$ hand in groups of right-handed subjects [16]. Cornwell et al. (2012) tested the hand grip strength in two groups of right - side dominant and left - side dominant subjects under bilateral and unilateral conditions [17]. They found no bilateral force deficits for either right or left hand in the right handed group. For the left handed subjects, only the dominant hand displayed a significant reduction in force in the bilateral compared to the unilateral condition. Our results confirmed partially these data, indicating symmetrical BD for peak of force in the RH group and asymmetrical BD in the $\mathrm{LH}$ group. However, some studies have shown asymmetrical BD in right-handed men $[9,10]$. These authors reported that the decrease of maximal hand strength during isometric bilateral contractions was higher for the dominant right hand. This finding was not confirmed thereafter in a group of right-handed young men [13]. In a previous study of ours, we found symmetrical $\mathrm{BD}$ in groups of right-handed male adults and adolescent oarsmen, and an asymmetrical BD in a group of right-handed untrained male adolescents [18]. The left/right asymmetry of the $\mathrm{BD}$ for peak of force found in the left-handed young men confirmed our hypothesis that asymmetry of bilateral strength deficit is not an established phenomenon and it depends on age, training and handedness. The mechanisms underlying bilateral deficit are not fully understood. Neural inhibition during bilateral contractions is the leading theory explaining bilateral deficit. Several investigators have described an interhemispheric inhibition of the motor cortex during bilateral contractions [13, 19]. They have reported a significant decrease in precentral gyrus activation during bilateral contractions, as compared with unilateral contractions, the decrease being accompanied by decreased force and muscle activation. On the other hand, Yahagi and Kasai (1999) reported that left-handed persons showed a much more variable asymmetry pattern of the motor cortex when compared with right-handed people [20]. Thus, the differences in the degree of hemispheric asymmetry in right- and left-handed subjects probably reflect the corresponding differences in the functional organization of bimanual isometric handgrip.

\section{Conclusions}

The main finding of this study was that the 10 percent rule is valid for right-handed subjects and does not apply to left- handed individuals. The $\mathrm{L} / \mathrm{R}$ ratios we found suggest that peak of force and rate of force are indicative for the handedness in right-handers only. The BL/UL ratios for peak of force indicated that bilateral strength deficit was present in both right- and left handed young men. However, in left-handed subjects the bilateral deficit was asymmetrical and it was greater for the dominant hand. Bilateral deficit for rate of force was found in the right handed men only and it was asymmetrical. Obviously, there are differences in the functional organization of bimanual isometric handgrip between right- and left handed young men.

\section{References}

1. Corey DM, Hurley MM, Foundas AL. Right and left handedness defined; A multivariate approach using hand preference and Hand performance measures. Neuropsychiatry Neuropsychol Behav Neurol. 2001;14(3):144-52.

2. Bryden PJ, Pryde KM, Roy EA. A performance measure of the degree of hand preference. Brain Cogn. 2000;44(3):402-14.

3. Petersen P, Petrick M, Connor H, Conklin D. Grip strength and hand dominance: challenging the 10\% rule. Am J Occup Ther. 1989;43(7):444-7.

4. Clerke A, Clerke J. A literature review of the effect of handedness on isometric grip strength differences of the left and right hands. Am J Occ Ther. 2001;55(2):206-11.

5. Bohannon RW. Grip strength: a summary of studies comparing dominant and nondominant limb measuremnts. Percept Motor Skill. 2003;96(3 Pt1):728-30.

6. Oppewal A, Hilgenkamp TI, van Wijck R, Evenhuis HM. The effect of handedness on grip strength in older adults with intellectual disabilities. Res Devel Disab. 2013;34(5):1623-9.

7. Ertem K, Inan M, Yologlu S, Elmali N, Harma A, Sahin S, Bora A. Effects of dominance, body mass index and age on grip and pinch strength. Isokinet 
Exerc Sci. 2003;11(4):219-23.

8. Koley S, Singh AP. Effect of hand dominance in grip strength in collegiate population of Amritsar, Punjab, India. Anthropologist. 2010;12(1):13-16.

9. Ohtsuki T. Decrease in grip strength induced by simultaneous bilateral exertion with reference to finger strength. Ergonomics. 1981;24(1):37-48.

10. Oda S, Moritani T. Maximal isometric force and neural activity during bilateral and unilateral elbow flexion in humans. Eur J Appl Physiol Occup Physiol. 1994;69(3):240-3.

11. Kuruganti U and Seaman K. The bilateral leg strength deficit is present in old, young and adolescent females during isokinetic knee extension and flexion. Eur J Appl Physiol. 2006; 97:322-26.

12. Samozino P, Rejc E, di Prampero PE, Belli A, Morin JB. Force-Velocity Properties' Contribution to Bilateral Deficit during Ballistic Push-off. Med Sci Sports Exerc. 2014;46(1):107-14.

13. Oda S, Moritani T. Movement-related cortical potentials during handgrip contractions with special reference to force and electromyogram bilateral deficit. Eur J Appl Physiol Occup Physiol. 1995;72(1-2):1-5.

14. Annett M. A classification of hand preference by association analysis. Br J Physiol. 1970;61(3):54558.
15. Kamarul T, Ahmad TS. Hand grip strength in the adult Malaysan population. J Orth Surg. 2006;14(2):172-7.

16. Van Dieën JH, Ogita FG, De Haan A. Reduced neural drive in bilateral exertions: a performancelimiting factor? Med Sci Sports Exerc. 2003;35(1):111-8

17. Cornwell A, Khodiguian N, Yoo EJ. Relevance of hand dominance to the bilateral deficit phenomenon. Eur J Appl Physiol. 2012;112:416372.

18. Gatev P, Gavrilenko T, Kolev N. Effects of maturity and training on bimanual ballistic isometrik handgrip. Acta Physol \& Pharm Bul. 2001;26(1/2):97-101.

19. Post M., van Diunen H, Steens A, Renken R, Kuipers B, Maurits B, Zijdewind I. Redused cortical activity during maximal bilateral contractions of the index finger. Neuroimage, 2007;35(1):16-27.

20. Yahagi S, Kasai T. Motor evoked potentials induced by motor imagery reve a functional asymmetry of cortical motor control in left and right handed human subjects. Neurosci Lett. 1999;276(3):185-8. 